\title{
Familial occurrence of warts, hypogammaglobulinemia, infections, and myelokathexis (WHIM) syndrome
}

\author{
Maciej Siedlar ${ }^{1}$, Zbigniew Rudzki², Magdalena Strach ${ }^{3}$, Elżbieta Trzyna ${ }^{4}$, \\ Anna Pituch-Noworolska ${ }^{1}$, Anita Błaut-Szlósarczyk ${ }^{1}$, Karolina Bukowska-Strakova ${ }^{1}$, \\ Marzena Lenart ${ }^{1}$, Tomasz Grodzicki ${ }^{3}$ and Marek Zembala ${ }^{1}$ \\ ${ }^{1}$ Department of Clinical Immunology, Polish-American Institute of Pediatrics, Jagiellonian University Medical College, \\ Cracow, Poland \\ ${ }^{2}$ Department of Pathology, Jagiellonian University Medical College, Cracow, Poland \\ ${ }^{3}$ Department of Internal Medicine and Geriatrics, University Hospital, Jagiellonian University Medical College, Cracow, \\ Poland \\ ${ }^{4}$ Department of Transplantology, Polish-American Institute of Pediatrics, Jagiellonian University Medical College, \\ Cracow, Poland
}

Received: 2008.06.19, Accepted: 2008.10.20, Published online first: 2008.12.01

\begin{abstract}
Introduction: Warts, hypogammaglobulinemia, infections, and myelokathexis (WHIM) syndrome is a rare immunodeficiency disorder with an autosomal-dominant pattern of inheritance and low fatality rate but significant lifelong morbidity. Materials and Methods: A 27-year-old mother of two children has been suffering from severe neutropenia and recurrent infections with the diagnosis of sporadic WHIM syndrome established by sequencing the CXCR4 gene and the finding of a heterozygous $1000 \mathrm{C} \rightarrow \mathrm{T}$ nonsense mutation in the second $C X C R 4$ exon. The first child was an apparently healthy boy delivered at full term. Umbilical cord blood cells were obtained for genetic analysis. Peripheral blood cells were also analyzed at 8 months of life. Both analyses revealed the same mutation as that of his mother. The child was in a good condition, manifesting neutropenia without infections until 11 months of life. He subsequently developed pneumonia requiring a more aggressive treatment. After that, the regular substitution of immunoglobulins (IVIGs) and G-CSF has been preventing serious infections. Six months ago the second boy was delivered who also demonstrated neutropenia without severe infections. Genetic studies using cord blood and also peripheral blood cells in the fourth month showed an identical mutation of the CXCR4 gene as in his mother. Moreover, the mother and her first son demonstrated monocytopenia.

Results: The results indicate that genetic defects connected with WHIM syndrome may influence not only the granulocyte, but also the monocytic lineage. Moreover, a perinatal diagnosis of WHIM syndrome made by sequencing the CXCR4 gene should be performed in cases where either parent is known to be affected with this disease.

Conclusions: This would facilitate an earlier detection of the deficiency in children, thereby allowing a more comprehensive follow-up and administration of appropriate therapy.
\end{abstract}

Key words: WHIM syndrome, myelokathexis, CXCR4, primary immunodeficiency, CD $14^{+} \mathrm{CD} 16^{+}$monocytes.

Corresponding author: Maciej Siedlar, M.D. Ph.D., Department of Clinical Immunology Polish-American Institute of Pediatrics, Jagiellonian University Medical College, Wielicka 265, 30-663 Cracow, Poland, tel./fax: + 48 12 658-17-56, e-mail: misiedla@cyf-kr.edu.pl

\section{INTRODUCTION}

Myelokathexis was introduced by Zeulzer [22] to describe a new form of chronic granulocytopenia characterized by an excessive bone marrow retention of peculiar senescent granulocytes with hypersegmented nuclear lobes. Later, the WHIM acronym was used to describe patients with viral warts, hypogammaglobulinemia, infections, and myelokathexis [20]. Patients with
WHIM syndrome demonstrate a significant variability of clinical symptoms [5]. Typically, severe non-cyclic neutropenia without an increase in neutrophil count during infections is observed [12, 13]. Quantitative and qualitative leukocyte abnormalities also affect lymphocytes, with a reduction in circulating naive $\mathrm{T}$ cells and memory $\mathrm{B}$ cells along with an increase in effector $\mathrm{T}$ cells [6]. Moreover, lymphopenia is observed and the low level of immunoglobulins implicates dysfunction of 
B cells [4]. Patients suffer from recurrent bacterial infections affecting mainly the respiratory tract, skin, middle ear, and gingiva which respond to antibiotic therapy. The skin symptoms include human papilloma virusinduced viral warts and erosions in the perianal region which are resistant to therapy [5]. Epstein-Barr virusrelated B-cell lymphomas were described in two patients $[3,9]$ and one patient with Kaposi sarcoma was reported, which may suggest an increased risk of lymphoid malignancies in WHIM syndrome, possibly induced by Herpes viruses [3].

Family studies imply an autosomal-dominant inheritance, while only one family was described with an apparent autosomal-recessive mode, explained by a paternal mosaicism [7]. The sporadic cases are rare and have so far been described mostly in women [19]. The identification of 23 candidate genes was based on whole autosome scans in three families with WHIM syndrome [7]. Mutations of the chemokine receptor CXCR4 family gene were finally recognized in pivotal association with this syndrome. Interactions between CXCR4 and its ligand CXCL12 (stromal-derived factor 1) are crucial for fetal hematopoiesis and the trafficking of hematopoietic cells [11, 16, 17]. All known CXCR4 mutations responsible for the WHIM phenotype are heterozygous and affect the C-terminal cytoplasmic tail of the protein with its truncation $[6,7,17]$. Subsequently, $\mathrm{T}$ lymphocytes and mature granulocytes of WHIM patients were shown to manifest an enhanced chemotactic response to CXCL12, which may explain the trapping of mature and senescent neutrophils within bone marrow and enhanced removal of mature granulocytes from the circulation [6]. The most frequent 1000 $\mathrm{C} \rightarrow \mathrm{T}$ mutation within the second $C X C R 4$ exon leads to altered receptor internalization and surface recovery pathways [10]. However, the exact mechanisms linking the profound abnormalities in CXCR4-CXCL12 signaling and the WHIM phenotype are not entirely clear. Moreover, in some WHIM patients a CXCR4 mutation was excluded by sequencing the whole gene $[2,7]$.

The present report describes a sporadic case of WHIM in a woman and the perinatal diagnosis of WHIM syndrome in her two newborn sons. This sporadic case was proved by $C X C R 4$ gene sequencing and forensic analysis of the appropriate family short tandem repeats (STRs) in three generations (grandparents, mother and sons). The affected children were first diagnosed by genetic analysis of cord blood cells. Because of the profound monocytopenia seen in the mother and her first son, two main subpopulations of monocytes, "classical" (CD14 $\left.{ }^{++} \mathrm{CD} 16^{-}\right)$and "proinflammatory" $\left(\mathrm{CD} 14^{+} \mathrm{CD} 16^{+}\right)$, were also analyzed.

\section{CASE PRESENTATION}

A 23-year-old woman was referred to the hospital for complex immunological tests with an initial diagnosis of common variable immunodeficiency (CVID) because of hypogammaglobulinemia. She had been suffering since childhood from recurrent sino-pulmonary infections; first pneumonia occurred in the second month of life with a white blood cell count of $0.3 \times 10^{9} / 1$. Leukopenia $\left(0.86 \times 10^{9} / 1\right)$ was noted again during the course of pneumonia at the age of 9 years. Upon diagnosing a non-cyclic leukopenia, therapy with subcutaneous (s.c.) GM-CSF or G-CSF was started. During the previous 5 years she was treated with antibiotics because of acute or exacerbant sinusitis and/or pneumonia. Vaginal, but not skin, warts were observed when she was 20 years old. The family history was negative; her parents, seven siblings, and other known relatives were free of significant infections or warts.

On admission she was in good condition, with a mild sinusitis. She responded poorly to antibiotics and G-CSF therapy. Two trephine bone marrow biopsies were performed, but the material was unsatisfactory to make a diagnosis. The results of laboratory tests on admission are shown in Table 1. Blood biochemistry and coagulation were within normal ranges. There were no symptoms of autoimmune disease and autoantibodies were absent. Ultasonography showed a slight splenomegaly and X-ray and CT scans revealed bilateral shading of the maxillary and frontal sinuses. The clinical history, present symptoms, and an immunological workup suggested a diagnosis of CVID. The therapy included intravenous immunoglobulin substitution with an initial dose of $0.6 \mathrm{~g} / \mathrm{kg}$ b.w. i.v. every 10 days followed by three infusions of $0.4 \mathrm{~g} / \mathrm{kg}$ every four weeks and G-CSF therapy (5 $\mu \mathrm{g} / \mathrm{kg}$ s.c. every second day). During the two-year therapy, pulmonary infections became less frequent. After 18 months of treatment, the next trephine bone marrow biopsy was performed. The morphological changes in the bone marrow were typical (see below) and WHIM syndrome was suspected. The diagnosis was confirmed by DNA sequencing.

After two years of therapy she became pregnant. The IVIG therapy was continued with a dosage of $0.6 \mathrm{~g} / \mathrm{kg}$ b.w. every three weeks, G-CSF was discontinued, and no complications were observed during pregnancy. The child was delivered by caesarian section at the 41 st week of pregnancy. Cord blood was taken for assessment of the CXCR4 gene sequence. The boy had a birth-weight of $2980 \mathrm{~g}$ and 8 points on the Apgar scale. No infections were recorded in the neonatal period. DNA sequencing studies showed a mutation similar to that found in the mother. On the 14th day of life he was admitted to the local hospital because of leukopenia, but neither G-CSF therapy was introduce nor immunological tests performed. At the age of 8 months, blood was taken for genetic and immunological tests (Table 1). The initial diagnosis of WHIM based on a cord blood assay was confirmed by sequencing CXCR4-DNA isolated from peripheral blood mononuclear cells. His general condition was good, his weight within the normal range for this age. A flat angioma of the occipital region was noted. The therapy included G-CSF (5 $\mu \mathrm{g} / \mathrm{kg}$ s.c.) and IVIG substitution (an initial dose of $0.25 \mathrm{~g} / \mathrm{kg}$ b.w. followed by 
Table 1. The results of immunological tests in mother and her children with WHIM syndrome

\begin{tabular}{|c|c|c|c|c|c|c|}
\hline \multirow{2}{*}{ Tests } & \multicolumn{2}{|c|}{ Mother } & \multicolumn{2}{|c|}{ Boy 1 at 8 months of life } & \multicolumn{2}{|c|}{ Boy 2 at 4 months of life } \\
\hline & tests results & normal range & tests results & normal range & tests results & normal range \\
\hline Granulocyte count $\left(\times 10^{9} / 1\right)$ & $\begin{array}{c}0.172 \\
(17.2 \% \text { of } \\
\text { normal value })\end{array}$ & $1.00-5.00$ & $\begin{array}{c}0.03 \\
(3.0 \% \text { of } \\
\text { normal value })\end{array}$ & $1.00-8.00$ & $\begin{array}{c}0.031 \\
(4.41 \% \text { of } \\
\text { normal value })\end{array}$ & $0.70-4.8$ \\
\hline $\begin{array}{l}\text { Lymphocyte count }\left(\times 10^{9} / 1\right) \\
\text { no }\end{array}$ & $\begin{array}{c}0.662 \\
(66 \% \text { of } \\
\text { normal value })\end{array}$ & $1.00-4.00$ & $\begin{array}{c}2.0 \\
(58.8 \% \text { of } \\
\text { normal value })\end{array}$ & $3.40-10.50$ & $\begin{array}{c}2.852 \\
(86.4 \% \text { of } \\
\text { normal value })\end{array}$ & $3.30-10.3$ \\
\hline \multicolumn{7}{|l|}{ Immunoglobulin level: } \\
\hline $\mathrm{IgG}^{*} \mathrm{~g} / 1$ & 4.30 & $7.00-16.00$ & 1.67 & $2.76-7.44$ & 2.50 & $2.66-7.01$ \\
\hline $\operatorname{Ig} \mathrm{A} g / 1$ & 0.37 & $0.67-3.67$ & $<0.06$ & $0.13-0.81$ & 0.07 & $0.07-0.37$ \\
\hline $\operatorname{IgM~g/l~}$ & 0.38 & $0.41-2.03$ & 0.17 & $0.26-1.34$ & 0.41 & $0.17-0.86$ \\
\hline \multicolumn{7}{|l|}{ Lymphocytes: } \\
\hline $\begin{array}{l}\text { B lymphocytes (CD19/ul) } \\
\text { T lymphocytes }\end{array}$ & 9 & $110-570$ & 80 & $610-2600$ & 6 & $135-2000$ \\
\hline CD3 $(/ \mu \mathrm{l})$ & 171 & $1000-2200$ & 1700 & $1900-5900$ & 1053 & $2500-5500$ \\
\hline CD4 $(/ \mu \mathrm{l})$ & 57 & 530-1300 & 1320 & $1400-4300$ & 806 & $1600-4000$ \\
\hline $\operatorname{CD} 8(/ \mu \mathrm{l})$ & 93 & 330-920 & 320 & $500-1700$ & 221 & $560-1700$ \\
\hline $\begin{array}{l}\mathrm{NK}\left(\mathrm{CD}^{-}, \mathrm{CD}^{-} 6^{+} / \mathrm{CD}^{-} 6^{+}\right) \\
\mathrm{l})\end{array}$ & 105 & $70-480$ & 180 & $160-950$ & 143 & $170-1100$ \\
\hline \multicolumn{7}{|l|}{ Lymphoproliferation } \\
\hline anti-CD3 (SI) & 1 & $>15$ & 2 & $>15$ & 92 & $>15$ \\
\hline $\mathrm{PHA}(\mathrm{SI})$ & 1 & $>15$ & 1 & $>15$ & 92 & $>15$ \\
\hline
\end{tabular}

*Before IVIG therapy.

Abbreviations: SI - stimulation index, PHA - phytohemagglutinin.

$0.5 \mathrm{~g} / \mathrm{kg}$ b.w.) from the 8 th month of life. At the age of 11 months he suffered from pneumonia with severe bronchospasms. The treatment with adrenalin, $\beta 2$ mimetics by inhalation, antibiotics, and steroids i.v. was effective. Since then the boy remains healthy under constant antiallergic therapy with preventive antibiotics, G-CSF administered every $48 \mathrm{~h}$, and IVIG every four weeks.

The second boy was born with a weight of $2800 \mathrm{~g}$ and 9 points on the Apgar scale six months ago. The tests using cord and peripheral blood (in the fourth month of life) showed a mutation, identical to that of his mother, of the CXCR4 gene and pronounced granulocytopenia since birth. He is in good condition and on G-CSF and IVIG (since the fourth month of life) therapy.

The presented children developed severe neutropenia as the first symptom of WHIM syndrome. The hypogammaglobulinemia was mild due to regular substitution of the mother during pregnancy. The appropriate substitution with IVIG is believed to prevent or diminish the severity of common infections; therefore the early diagnosis of the children allowed treatment according to the gradual development of clinical symptoms of WHIM syndrome. The first child received IVIG from the eighth month of life, but despite this he developed severe pneumonia at the age of 11 months. After that there were no serious infections despite persistent neutropenia. It seems that IVIG substitution therapy might have been introduced too late in this case. Therefore, IVIG preparations were introduced in the second son in the fourth month of life and until now (the sixth month) he has not had severe infections. Nevertheless, IVIG may not completely prevent, but only significantly reduce, the incidence of respiratory tract infections in immunodeficient children, as was already shown in common variable immunodeficient patients [14].

\section{MATERIALS AND METHODS}

\section{Tissue samples}

The blood and bone marrow samples from the mother and blood samples from her parents were analyzed. Cord and peripheral blood from the newborns was also studied. Trephine bone marrow biopsies obtained from the superior/inferior iliac crest of the mother using Jamshidi needles were routinely fixed in buffered formalin, decalcified in acid-based medium (Shandon TBD- ${ }^{\mathrm{TM}}$ Decalcifier, Thermo Electronic Corporation, Runcorn, UK), embedded in paraffin, and cut into 3- to $4-\mu \mathrm{m}$ sections. The sections were stained with hematoxylin and eosin (H\&E), Gomori silver, Giemsa, and PAS methods. Bone marrow and peripheral blood smears were routinely stained with May-GrunwaldGiemsa. The parents and grandparents gave informed consent to participate in the study, which was also approved by the ethics review board of the Jagiellonian University Medical College (permission No. KBET/107/ /B/2006). 
Sequencing the CXCR4 gene

Both exons of the $C X C R 4$ gene were sequenced to look for mutations typical of WHIM syndrome. DNA was extracted with a QIAmp DNA Mini Kit (Qiagen, Germany) according to the manufacturer's instructions. PCR has been performed in a total volume of $20 \mathrm{ml}$, with $100 \mathrm{ng}$ of spectrophotometrically quantified DNA, $0.5 \mathrm{U}$ of DNA polymerase (Promega, WI, USA), 1.5 $\mathrm{mM} \mathrm{MgCl} 2,200 \mu \mathrm{M} \mathrm{dNTP}$, and $0.5 \mu \mathrm{M}$ of primers specific to the second exon of the CXCR4 gene (sense: 5'-TCC TCA TCC TGG CTT TCT TC, antisense: 5'-GCA TAA ACA GCT GGG GAT CA). The PCR cycles were 1 min. at $95^{\circ} \mathrm{C}$ followed by 35 amplification cycles $\left(95^{\circ} \mathrm{C}\right.$ for $45 \mathrm{~s}, 65^{\circ} \mathrm{C}$ for $45 \mathrm{~s}, 72^{\circ} \mathrm{C}$ for $\left.1 \mathrm{~min}\right)$ and final incubation at $4^{\circ} \mathrm{C}$ until the analysis commenced. The PCR products were purified with a QIAquick Gel Extraction Kit (Qiagen).

Sequencing PCR was performed on the PCR products with using fluorescently labeled nucleotides (Big Dye Terminator v3.1 Cycle Sequencing Kit, Applied Biosystems, CA, USA) and exon-specific primers. The PCR reaction parameters were as follows: reaction mix - 10 ng DNA mixed with $8 \mu$ l Terminator Ready Reaction Mix, $3.2 \mathrm{pM}$ of each primer in a final volume of $20 \mu \mathrm{l}$, PCR cycles $-1 \mathrm{~min}$ at $96^{\circ} \mathrm{C}$ followed by 25 amplification cycles $\left(96^{\circ} \mathrm{C}\right.$ for $10 \mathrm{~s}, 50^{\circ} \mathrm{C}$ for $5 \mathrm{~s}, 60^{\circ} \mathrm{C}$ for $4 \mathrm{~min}$ ) and held at $4^{\circ} \mathrm{C}$ for purification.

The PCR products were purified by ethanol/EDTA precipitation. The PCR products were dissolved in 25 $\mu l$ of Template Suppression Reagent (Applied Biosystems), denatured, and run on the Applied Biosystems 310 sequencing apparatus and analyzed with the Sequencing Analysis software (Applied Biosystems).

\section{PCR-STR forensic analysis: family study}

DNA was extracted from fresh whole blood of the mother (WHIM syndrome) and her parents, as described above. The test was performed with an AmpFlSTR SGM Plus PCR Amplification Kit (Applied Biosystems). PCR was performed using fluorescently labeled primers. PCR reaction: $21 \mu \mathrm{l}$ AmpFISTR PCR Reaction Mix, $1 \mu$ l polymerase Ampli Gold, 11 $\mu \mathrm{l}$ AmpFISTR SGM Plus Primer Set, and 1-2.5 ng DNA. The cycling conditions were $95^{\circ} \mathrm{C}$ for $11 \mathrm{~min}$, $94^{\circ} \mathrm{C}$ for $1 \mathrm{~min}, 59^{\circ} \mathrm{C}$ for $1 \mathrm{~min}, 72^{\circ} \mathrm{C}$ for $1 \mathrm{~min}$ for 28 cycles, $60^{\circ} \mathrm{C}$ for $45 \mathrm{~min}$, and final incubation at $25^{\circ} \mathrm{C}$ until ready for the analysis. The fluorescently labeled PCR products were run on the Applied Biosystems 310 sequencing apparatus and analyzed with 310 GeneScan3.1.2 software.

\section{Monocyte staining and analysis}

The patients' blood samples $(200 \mu \mathrm{l})$ were washed with $3 \mathrm{ml}$ of $0.9 \% \mathrm{NaCl}$ in polypropylene round-bottom tubes (Falcon, Becton Dickinson Biosciences/ /Pharmingen: BD, Belgium) and $100 \mu \mathrm{l}$ of the $200 \mu \mathrm{l}$ of cell suspension left after centrifugation was put into a TruCount Tube with microbeads (BD). Then the cells were stained on ice for $30 \mathrm{~min}$ with $5 \mu \mathrm{l}$ of anti-CD45-APC (\#340910, clone 2D1; BD), -HLA-DR-PerCP (\#347402, clone L243; BD), -CD14-FITC (\#6603511, clone MY4, Beckman-Coulter, Ireland), and -CD16-PE (\#332779, clone Leu11c; BD) monoclonal antibodies. The samples were then treated with $400 \mu \mathrm{l}$ of FACS Lysing Solution (BD) for 3-5 min until erythrocytes were lysed and the cells were immediately acquired on a FACSCanto (BD) flow cytometer along with 10,000 beads, then analyzed with FACSDiva Software (BD, CA, USA). The absolute numbers of $\mathrm{CD} 14^{+} \mathrm{CD} 16^{+}$and $\mathrm{CD} 14^{++} \mathrm{CD} 16^{-}$monocytes were calculated based on the acquired bead count (10,000 in each sample) according to the manufacturer's instructions.

\section{RESULTS}

\section{Bone marrow morphology}

The bone marrow of the mother showed high cellularity with an excess of myeloid cells, mostly hypersegmented (senescent) neutrophils (Fig. 1). A uniform but very narrow paratrabecular rim of promyelocytes was present. Normal topography and undisturbed maturation pattern of erythroid cells and megakaryocytes were noted. There was no increase in lymphoid cells, mast cells, or blasts. Also, minimal widespread reticulin fibrosis and distended blood vessels were seen. Bone marrow and peripheral blood smears confirmed the characteristic abnormalities of granulocytes, with a marked nuclear hypersegmentation, thin and long chromatin filaments connecting the nuclear lobes, and abnormal variability in nuclear lobe sizes.

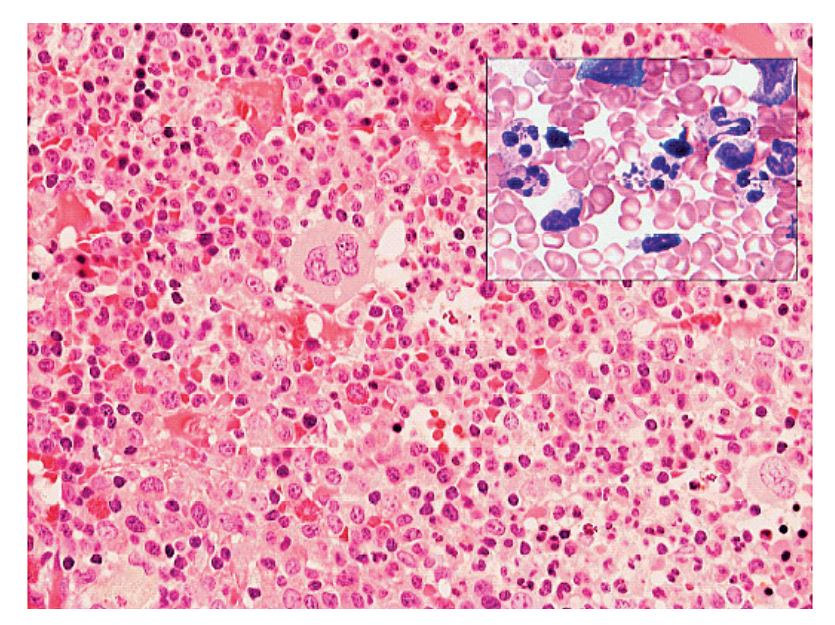

Fig. 1. Highly cellular bone marrow biopsy of the WHIM-mother, with increased mature neutrophil granulocytes showing prominent nuclear segmentation. Inset: bone marrow smear reveals abnormal nuclear segmentation patterns, including variability in nuclear lobe sizes and unusually slender chromatin filaments connecting the nuclear lobes. 


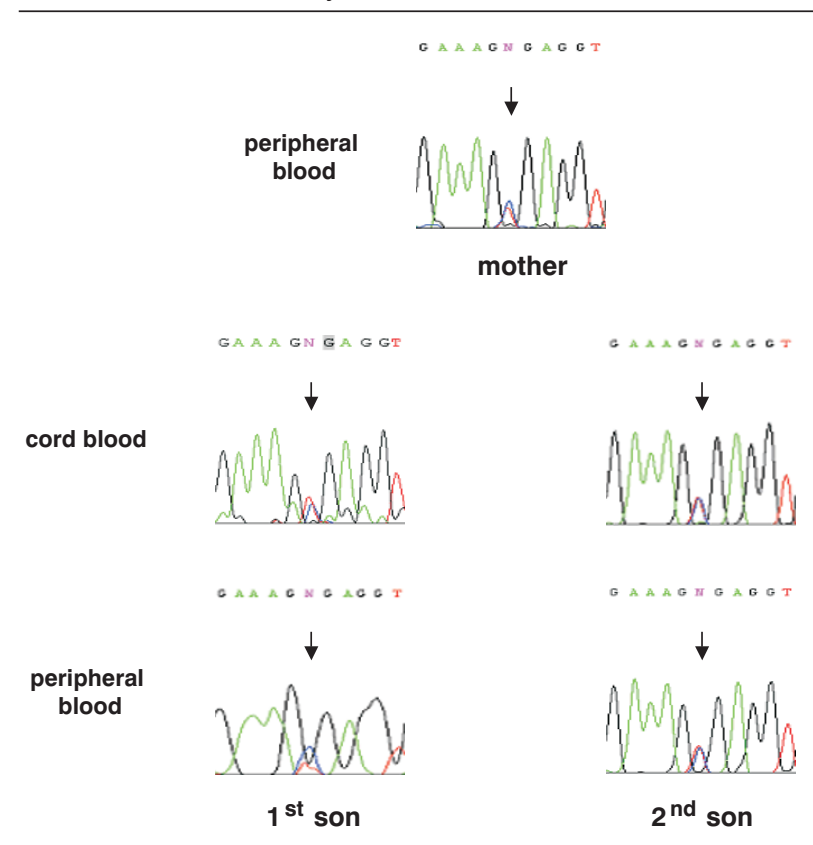

Fig. 2. Electropherograms of a portion of the CXCR4 gene's second exon of the mother and her children with WHIM syndrome show $\mathrm{C} \rightarrow \mathrm{T}$ heterozygosity at position 1000 in the cDNA sequence. Cord blood and peripheral blood collected from the children in the eighth (first son) and fourth (second son) months of life were taken for the study.

\section{Genetic studies}

No mutations on the first exon of the $C X C R 4$ gene were found. The studies concentrated on mutations on the second exon associated with changes in the intracellular tail domain essential for CXCR4 protein internalization [7]. The only observed change was $\mathrm{C} \rightarrow \mathrm{T}$ heterozygosity at the base corresponding to position 1000 in the CXCR4-DNA second exon sequence leading to a TGA stop codon. The observed nonsense mutation may cause shortening of the cytoplasmatic tail of CXCR4 protein. Such mutations were observed in the mother and in both her sons in the cells taken from cord and peripheral blood (Fig. 2). No such changes were found in the grandparents (data not shown). Neither the previously described [7] deletion of CT dinucleotide at position 1016-1017 nor a $\mathrm{G} \rightarrow \mathrm{T}$ change at position 1027 were found in the cDNA sequences. Forensic analysis of all 11 tested STR loci of the mother's DNA revealed alleles specific to her parents, corroborating the notion of the spontaneous character of CXCR4 mutation in the mother, which had occurred in chromosome 2 of one of the parents of the proposita.

\section{Immunological tests}

The immunological tests showed a lowered level of immunoglobulins of all classes in the mother and both her sons (apart from $\operatorname{IgM}$ in the second son) and markedly lowered absolute numbers of B (CD19+) lymphocytes in the mother and first son. Low numbers of
$\mathrm{T}$ lymphocytes in the mother and an inverse ratio of CD4:CD8 were noted. Borderline numbers of T lymphocytes were observed in the children. There were no responses to mitogen and CD3 stimulation in the mother and first son (Table 1).

A low number of "proinflammatory" CD $14^{+} \mathrm{CD} 16^{+}$ monocytes in the mother $(1$ cell/ $\mu \mathrm{l}$; Fig. $3 \mathrm{C})$ and in the first son (10 cells $/ \mu 1$; Fig. $3 \mathrm{E})$ was also observed. The numbers of "classical" CD14 ${ }^{++} \mathrm{CD} 16^{-}$monocytes were also decreased in both patients $(59$ cells/ $\mu$ l and 110 cells $/ \mu$ l, respectively; Figs. $3 \mathrm{C}, \mathrm{E}$ ). In our material the numbers of $\mathrm{CD} 14^{+} \mathrm{CD} 16^{+}$monocytes in healthy adult volunteers (over 18 years old) were $66 \pm 31$ cells $/ \mu \mathrm{l}$ $(n=17)$ and in children $58 \pm 34$ cells $/ \mu l(n=60)$. The numbers of $\mathrm{CD} 14^{++} \mathrm{CD} 16^{-}$monocytes were, respectively, $549 \pm 233$ cells $/ \mu 1$ and $430 \pm 158$ cells $/ \mu l$. The plots in Figs. $3 \mathrm{~B}$ and $3 \mathrm{D}$ are representative of age-matched blood donors without immunodeficiency.

\section{DISCUSSION}

The clinical and laboratory findings of WHIM syndrome are very typical; however, in practice the correct diagnosis may be delayed due to the rarity of the disease. In keeping with this, the reported case of sporadic WHIM syndrome was not definitely diagnosed in the mother until the age of 23 years, although the first symptoms occurred in the early childhood. The initial diagnosis of CVID was corrected after bone marrow examination, when hypercellularity with senescent granulocytes was noted. Although the clinical course was mild, the response to antibiotic therapy was limited. IVIG substitution resulted in a decrease in the frequency of infections. The response to G-CSF was rather poor; neutropenia was observed, but it seemed clinically silent. The mechanism of mobilization of neutrophil release from the bone marrow via desensitization of CXCR2 and increased signaling through the mutated CXCR4 by the pathogen might be the explanation [4]. The sons, born with proper weights and without symptoms of the disease, were diagnosed with WHIM syndrome based on DNA sequencing of cord blood cells and the presence of the mutation identical to that observed in the mother. Although neutropenia was observed, the first serious infection occurred in first son at 11 months of life, despite IVIG substitution and GCSF therapy.

Myelokathexis is a morphological phenomenon highly suggestive of WHIM syndrome, but it is probably not entirely specific to this disease $[15,18]$. A bone marrow examination of the mother revealed a limited response to G-CSF (inadequate promyelocyte mobilization), which is observed in patients with WHIM syndrome. The results of our study suggest that the defect in granulocyte function in WHIM is not limited to the postulated accumulation of senescent granulocytes in the bone marrow, but may also affect their development and maturation as well as the development and function 

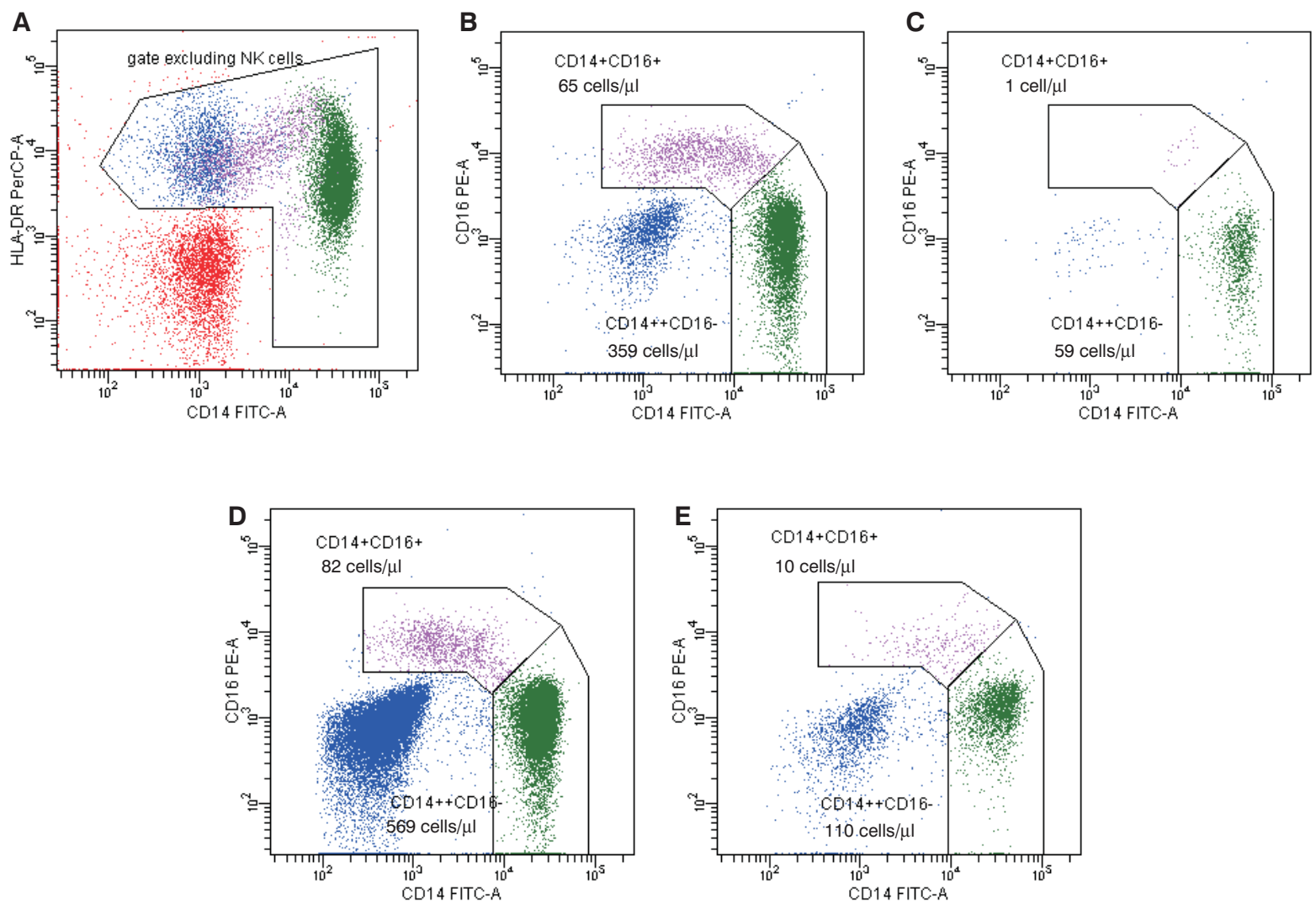

Fig. 3. Analysis of the $\mathrm{CD} 14^{+} \mathrm{CD} 16^{+}$and $\mathrm{CD} 14^{++} \mathrm{CD} 16^{-}$subpopulations of monocytes. The gate was first set on a "CD45 vs. Side Scatter" dot plot around the CD45-positive monocytes and adjacent lymphocytes (data not shown). These cells were then gated to exclude the CD14-HLA-DR ${ }^{-}$NK cell population (A) and finally analyzed with respect to CD14 and CD16 antigen expression (B). Analyses of a typical healthy adult (B) and healthy child (D) as well as the mother with WHIM syndrome (C) and her first son (E) are shown.

of $\mathrm{T}$ and $\mathrm{B}$ cells (low levels of lymphocytes and immunoglobulins; Table 1) and perhaps monocytes. The numbers of "proinflammatory" $\mathrm{CD} 14^{+} \mathrm{CD} 16^{+}$ monocytes [20] and, to a lesser extent, "classical" CD14 ${ }^{++}$CD $16^{-}$monocytes were significantly diminished in the peripheral blood of the mother and her first son in comparison with age-matched controls (Fig. 3 B-E). The expression of CXCR4 molecule was higher on monocytes obtained from WHIM patients than on those from healthy persons (data not shown). This might be associated with disturbed chemothaxis of monocytes and/or granulocytes from niches with a high concentration of CXCL12 in the bone marrow as well as macrophages in tissues. Together this suggests that the proinflammatory response of macrophages, as well as antigen presentation, may not be as effective as in healthy individuals. Therefore, GM-CSF and/or IFN- $\gamma$ herapy may be superior to G-CSF substitution in patients refractory to this cytokine, but this requires additional studies.

The preference to female gender is characteristic of the sporadic form of WHIM [1, 4, 8, 19]. The clinical course is rather mild and neutropenia is the main recognized and diagnosed symptom. The rarity of WHIM syndrome and the clinical variations in the combinations of symptoms (e.g. warts observed in the second decade and absent in children) are associated with the delay in the correct diagnosis. The possibility of infection-derived mobilization of neutrophils and good response to G-CSF and antibiotics in the majority of patients prevents a life-threatening course of infections. Women with WHIM syndrome may have normal pregnancy and delivery, but whether the children are affected depends on the type of heredity of WHIM syndrome.

To summarize, we have presented a case of sporadic WHIM syndrome in a young woman whose both sons also turned out to have inherited the same mutation. The diagnosis was made in the perinatal period by genetic analysis of the CXCR4 gene in cord blood cells. Despite significant progress in genetics and pathophysiology, the diagnosis of WHIM may still depend on careful observation of cytological features of defective hematopoiesis in patients with clinical symptoms of immunodeficiency with neutropenia. It is suggested that perinatal diagnostics of WHIM syndrome based on a molecular DNA analysis of cord blood cells should be performed in cases of pregnancy of affected mothers.

Acknowledgment: This work was supported by the National Committee for Scientific Research grant No. 3220/PO1/2007/ 132 . 


\section{REFERENCES}

1. Alapi K., Erdos M., Kovacs G. and Marodi L. (2006): Recurrent CXCR4 sequence variation in a girl with WHIM syndrome. Eur. J. Haematol., 78, 86-88.

2. Balabanian K., Lagane B., Pablos J.L., Laurent L., Planchenault T., Verola O., Lebbe C., Kerob D., Dupuy A., Hermine O., Nicolas J. F., Latger-Cannard V., Bensoussan D., Bordigoni P., Baleux F., Le Deist F., Virelizier J. L., Arenzana-Seisdedos F. and Bachelerie F. (2005): WHIM syndrome with different genetic anomalies are accounted for impaired CXCR4 desensitization to CXCL12. Blood, 105, 2449-2457.

3. Chae K. M., Ertle J. O. and Tharp M. D. (2001): B-cell lymphoma in patient with WHIM syndrome. J. Am. Acad. Dermatol., 44, 124-128.

4. Diaz G. A. (2005): CXCR4 mutations in WHIM syndrome: a misguided immune system. Immunol. Rev., 203, 325-243.

5. Gorlin R. J., Gelb B., Diaz G. A., Lofsness K. G., Pittelkow M. R. and Fenyk J. R. Jr. (2000): WHIM syndrome, an autosomal dominant disorder: clinical, haematological and molecular studies. Am. J. Med. Genet., 91, 368-376.

6. Gulino A. V., Moratto D., Sozzani S., Cavadini P., Otero K., Tassone L., Imberti L., Pirovano S., Notarangelo L. D., Soresina R., Mazzolari E., Nelson D. L., Notarangelo L. D. and Badolato R. (2004): Altered leukocyte response to CXCL12 in patients with warts, hypogammaglobulinemia, infections, myelokathexis (WHIM) syndrome. Blood, 104, 444-452.

7. Hernandez P. A., Gorlin R. J., Lukens J. N., Taniuchi S., Bohinjec J., Francois F., Klotman M. E. and Diaz G. A. (2003): Mutations in the chemokine receptor gene CXCR4 are associated with WHIM syndrome a combined immunodeficiency disease. Nat. Genet, 34, 70-74.

8. Hord J. D., Whitlock J. A., Gay J. C. and Lukens J. N. (1997): Clinical features of myelokathexis and treatment with hematopoietic cytokines: a case report of two patients and review of literature. J. Pediatr. Hematol. Oncol., 19, 443-448.

9. Imashuku S., Miyagawa A., Chiyonobu T., Ishida H., Yoshihara T., Teramura T., Kuriyama K., Imamura T., Hibi S., Morimoto A. and Todo S. (2002): Epstein-Barr virus associated T-lymphoproliferative disease with hemophagocytic syndrome followed by fatal intestinal B lymphoma in young adult female with WHIM syndrome. Ann. Hematol., 81, 470-473.

10. Kawai T., Choi U., Whiting-Theobald N. L., Linton G. F., Brenner S., Sechler J. M., Murphy P. H. and Malech H. (2005): Enhanced function with decreased internalization of carboxy-terminus truncated CXCR4 responsible for WHIM syndrome. Exp. Hematol., 33, 460-468.
11. Kucia M., Jankowski K., Reca R., Wysoczynski M., Bandura L., Allendorf D. J., Zhang J., Ratajczak J. and Ratajczak M. Z. (2004): CXCR4-SDF-1 signaling, locomotion, chemotaxis and adhesion. J. Mol. Histol., 35, 233-245.

12. Mentzer W. C. Jr., Johnston R. B. Jr., Baehner R. L. and Nathan D. G. (1977): An unusual form of chronic neutropenia in father and daughter with hypogammaglobulinemia. Br. J. Haematol., 36, 313-322.

13. O'Regan S., Newman A. J. and Grahan R. C. (1977): "Myelokathexis". Neutropenia with marrow hyperplasia. Am. J. Dis. Child, 131, 655-658.

14. Pourpak Z., Aghamohammadi A., Sedighipour L., Farhoudi A., Movahedi M., Gharagozlou M., Chavoshzadeh Z., Jadid L., Rezaei N. and Moin M. (2006): Effect of regular intravenous immunoglobulin therapy on prevention of pneumonia in patients with common variable immunodeficiency. J. Microbiol. Immunol. Infect., 39, 114-120.

15. Rassam S. M., Roderick P. al-Hakim I. and Hoffbrand A. V. (1989): A myelokathexis-like variant myelodysplasia. Eur. J. Haematol., 42, 99-102.

16. Ratajczak M. Z., Zuba-Surma E., Kucia M., Reca R., Wojakowski W. and Ratajczak J. (2006): The pleiotropic effects of the SDF-1-CXCR4 axis in organogenesis, regeneration and tumorigenesis. Leukemia, 20, 1915-1924.

17. Sanmun D., Garwicz D., Edvard Smith C. L., Palmblad J. and Fadeel B. (2006): Stromal-derived factor-1 abolishes constitutive apoptosis of WHIM syndrome neutrophils harbouring a truncating CXCR4 mutation. Br. J. Hematol., 134, 640-644.

18. Sheridan B. L., Pinkerton P. H., Curtis J. E., Tepperman A. D. and Hunt A. J. (1991): The myelokathexis-like variant of myelodysplastic syndrome - the second example. Clin. Lab. Haematol., 13, 81-85.

19. Tarzi M. D., Jenner M., Hattotuwa K., Faruqi A. Z. Diaz G. A. and Loghurst H. J. (2005): Sporadic case of warts, hypogammaglobulinemia, immunodeficiency and myelokathexis syndrome. J. Allergy Clin. Immunol., 116, $1101-1105$.

20. Wetzler M., Talpaz M., Kleinerman E. S., King A., Huh Y. O., Gutterman J. U. and Kurzrock R. (1990): A new familial immunodeficiency disorder characterized by severe neutropenia a defective marrow release mechanism and hypogammaglobulinemia. Am. J. Med., 89, 663-672.

21. Ziegler-Heitbrock L. (2007): The $\mathrm{CD} 14^{+} \mathrm{CD} 16^{+}$blood monocytes: their role in infection and inflammation. J. Leukoc. Biol., 81, 584-592.

22. Zueler W. W. (1994): Myelokathexis - a new form of chronic granulocytopenia. Case report. N. Engl. J. Med., 270, 699-704. 